\title{
Addressing the high levels of psychological distress in law students through intentional assessment and feedback design in the first year law curriculum
}

\author{
Rachael Field and Sally Kift \\ Faculty of Law \\ Queensland University of Technology
}

\begin{abstract}
A study of the Brain and Mind Research Institute released in 2009 established that more than one third of Australian law students suffer from psychological distress. The psychological health of law students is therefore a critical issue for Australian legal education, and strategic change is necessary to address the stressful nature of studying law. This paper argues that intentional first year curriculum design has a critical role to play in addressing and preventing psychological distress in law students. In particular, we argue that assessment and feedback practice in the first year can be harnessed to assist students to successfully transition to studying law at university by supporting their development as independent and self-managing learners, and assisting their acquisition of the necessary tertiary literacies. First, we consider the problem of psychological distress in law students. Second, we explore a range of theoretical and practical strategies to assist the implementation of good assessment and feedback practice in the first year of legal education. The paper concludes that intentional assessment and feedback design in the first year of law is critical to alleviating psychological distress levels in law students.
\end{abstract}

Please cite this article as:

Field, R. \& Kift, S. (2010). Addressing the high levels of psychological distress in law students through intentional assessment and feedback design in the first year law curriculum. The International Journal of the First Year in Higher Education, 1(1), 65-76.

This article has been peer reviewed and accepted for publication in Int J FYHE. Please see the Editorial Policies under the 'About' section of the Journal for further information.

(C) Copyright of articles is retained by author/s. As an open access journal, articles are free to use, with proper attribution, in educational and other non-commercial settings. ISSN: 1838-2959 


\section{Introduction}

The psychological health of law students is a critical issue for Australian legal education. A recent study has evidenced that $35 \%$ of law students experience high levels of psychological distress. These levels are $17 \%$ higher than those experienced by medical students, and more than $20 \%$ higher than those experienced by the general population. The competitive, isolating, and adversarial learning environment at law school has been suggested as partly responsible (Brain and Mind Research Institute [BMRI], 2009), and the problem has been identified as beginning "during the first semester of law school" (Iijima, 1998, p. 524). In order to address the high levels of psychological distress experienced by law students, strategic change is necessary to the way we design and deliver legal curriculum.

Intentional curriculum design has a critical role to play in enhancing first year student engagement, success and retention (Kift, 2008). Curriculum design that delivers good assessment and feedback practice is particularly important in this regard because "for most students, assessment requirements literally define the curriculum" (James, McInnis \& Devlin, 2002, p. 7). Indeed, assessment can be said to be "at the heart of the student experience" (Brown \& Knight, 1994, p. 12). The argument of this paper is that supportive assessment and feedback strategies in the first year of legal education can work to address and prevent psychological distress in law students as a first year learning engagement and retention intervention. This is because assessment and feedback approaches can be purposefully harnessed to assist students to make the successful transition to higher education and its expectations regarding assessment products and processes (First Level Assessment and Feedback Project [FLAP], 2009; Kift, 2008; Nicol, 2009): careful assessment design can help students to become independent and self-managing learners, and can assist students to acquire necessary tertiary assessment literacies (Orrell, 2005). By facilitating student development in this way, assessment and feedback design strategies have the significant potential to alleviate student anxiety about their studies, and thereby contribute to addressing and assuaging the high psychological distress levels experienced by law students.

First, this paper considers the problem of psychological distress in law students. Second, we explore a range of theoretical and practical curriculum design strategies to assist the implementation of good assessment and feedback practice in the first year of legal education. The paper concludes that the clear and consistent provision of assessment information, instructions, guidance, and performance indicators to students, together with early and regular formative feedback on their work, are critical to alleviating psychological distress levels in first year law students.

\section{Psychological distress in law schools}

Law school is a psychologically distressing place for students. This has long been acknowledged by legal academics (Beck \& Burns, 1979; Watson, 1968) and is evident for example in the high attrition rate for law which has hovered annually around $20 \%$ for some time. Only recently however has the Brain and Mind Research Institute of the University of Sydney (BMRI, 2009) empirically established that Australian law students suffer disproportionately high levels of psychological distress. According to the BMRI, the results for law students indicated "a much higher level than expected of reported psychological distress and risk of depression on all measures used" (p. 37). Psychological distress levels in the practising legal profession itself are also high (Thomson, 2007, p. 18). The BMRI Report 
indicated that one in three solicitors experiences high to very high levels of psychological distress, although barristers' levels were lower at one in five. The Legal Services Commissioner for Queensland posits that emotional distress features in $30 \%$ of the disciplinary matters dealt with by his Commission (Britton, 2009, p. 1).

The role of legal education in the mental health of law students and the legal profession is highlighted by suggestions that the psychological distress experienced is a direct result of the way the law and legal culture are taught (Britton, 2009, p.3; Stuckey et al., 2007, pp. 29-37). Iijima (1998) asserts that the problems "begin during the first semester of law school" (p. 524).

The BMRI research confirms what the US legal education literature has been arguing for some time. In a study in 1986, Benjamin and colleagues found that symptoms of psychological distress rose significantly for students in their first year of law (compared to levels in the general population at that time), and persisted throughout the degree to postgraduation. The symptoms of psychological distress identified in that study included depression, obsessive compulsive behaviour, feelings of inadequacy and inferiority, anxiety, hostility, paranoia, social alienation and isolation (Benjamin, Kaszniak, Sales \& Shanfield,1986).

The BMRI Report does not offer definitive causes for why law students experience such high levels of psychological distress. However, it suggests that the competitive and adversarial nature of both legal education and legal culture are perhaps two causes in the Australian context. The US literature supports this analysis. Hess $(2002$, p. 75) for example writes that students experience law school as a competitive and alienating place where they lose their self-confidence, their motivation, and their passion for learning. It is also possible that low levels of student engagement contribute to the high psychological distress levels of law students. The 2008 Australasian Survey of Student Engagement (AUSSE) Report (Australian Council for Educational Research [ACER], 2009) confirms that universities need to work strategically to improve student engagement. That data demonstrates that, across the sector, universities are not scoring well (on a metric of 1-100) in relation to a range of engagement scales. For example, the scale result for student experiences of active learning was 37.9; for student/staff interactions it was 22.2; for enriching education experiences it was 25.0; and for supportive learning environments the scale result was 53.1. Of particular relevance to the argument of this paper is the additional AUSSE finding that only $38.6 \%$ of first year students considered that they had "often" or "very often" received prompt written or oral feedback from teachers or tutors on their academic performance. (It is also noteworthy that Krause, Hartley, James and McInnis (2005) have found that when first year students do receive feedback, only $33 \%$ of them consider it helpful).

Psychological distress in law students is therefore a current and significant issue to be addressed by legal educators. How should this be done? The BMRI Report notes that "mental illness and psychological distress are often portrayed in the popular media as issues relating to individuals" (2009, p. 43). However, the Report emphasises that the psychological health of law students is in fact "a problem for communities" (p. 43). Action on this issue is therefore the responsibility of the Australian legal academic community. In fact, now that there is empirical evidence confirming that legal educators contribute to student psychological distress, we consider it to be an ethical responsibility of legal educators to work to ameliorate that distress, to create positive learning experiences for our students, and 
to do no harm through legal education. As Hall (2009) notes, this means that the legal academy must overcome its cognitive dissonance as well its rationalisation tendencies on this issue.

It must be acknowledged that a range of education and information strategies are currently in place for university staff and students on issues of student mental health and well-being in Australian tertiary institutions. These approaches are generally the initiative of counselling, equity and disability support services (BMRI, 2009, pp. 44-45). For example, the Australian Law Students Association (2009) released a Handbook on Depression in Australian Law Schools in 2009, providing information for students as well as for Student Associations regarding mental health and coping with stress at law school.

It is important to continue to educate and inform. However, this paper argues for the legal academy to move beyond information provision to intentional curriculum design strategies to address and proactively prevent the high levels of psychological distress that law students are experiencing. A range of reports on legal education suggest that significant curriculum opportunities exist in legal education to better engage, motivate and support student learning (Johnstone \& Vignaendra, 2003; Stuckey et al., 2007; Sullivan, Colby, Wegner, Bond \& Shulman, 2007). Hess (2002) however notes that legal academics have not capitalised on the opportunities presented by the legal curriculum to address psychological distress. In particular, we believe that intentional design strategies for assessment and feedback practice in the first year of legal education can be used to alleviate student anxiety and stress, and thereby work towards addressing and preventing the high levels of psychological distress that law students currently experience. The next sections explore some practical ways in which this might be done, drawing on research conducted under Kift's ALTC Senior Fellowship that articulated a research-based "transition pedagogy" for the first year experience (Kift, 2008; Kift \& Nelson, 2005).

\section{Addressing the high levels of psychological distress experienced by law students through intentional assessment design strategies in the first year of legal education}

Whilst it seems trite to suggest that the efficacy and robustness of assessment design are critical in the first undergraduate year of tertiary study, until recently, there has been little extensive scrutiny of first year assessment practices. There has also been little promotion of assessment and feedback as an important first year learning intervention. In this section we explore three key assessment design strategies to alleviate student anxiety around assessment and thereby support student mental health: designing assessment that is clear about what is expected of students; designing assessment that engages students by scaffolding and integrating assessment within the curriculum; and designing assessment to encourage students to be independent learners.

\section{Designing assessment that is clear about what is expected of students}

Most commencing undergraduate students are unfamiliar with tertiary assessment practices and are uncertain about assessment expectations in relation to both assessment products (i.e., the types of assessment they will encounter), and assessment processes (i.e., the academic skills required to complete assessment tasks). Uncertainty about assessment causes student anxiety. For this reason, assessment in the first year, and particularly in the first semester of the first year, should be designed intentionally to alleviate foreseeable student anxiety. In 
particular, students should be assisted in understanding the nature of the tasks set and the type and standards of evidence required to prove their achievements. Being explicit about what is required for success, or in other words letting students into the secrets of assessment success, is a critical way of equitably unpacking for new students the culture of higher education learning. As Lawrence (2005), citing Benn (2000), says, we need "not only to explain and make clear the rules, but also to make explicit the hidden agendas, the covert or hidden curriculum, the implicit expectations and the expected (but not stated) behaviours intrinsic to achieving success in their discipline" (p. 23). How might this be done? Below we outline two assessment design approaches to assist students to understand assessment expectations, and thereby reduce stress and anxiety. The first involves helping students to understand academic languages and conventions, the second, involves helping students to understand assessment standards.

To engage productively with assessment tasks, first year students need explicit induction into the academic languages and conventions of higher education. This is particularly the case for legal education which has a range of assessment customs and conventions that are particular to it (such as legal reasoning and footnoting). Kift and Moody (2009) have outlined the following enablers for designing assessment that is explicit in its articulation of assessment expectations:

- Explaining the meaning of, and then consistently using, particular verbs in assessment tasks: for example, words such as "explain" or "discuss";

- Consistently naming assessment tasks across a degree program and explicitly clarifying what is expected in terms of the presentation of assessment tasks in a scholarly way: for example, how to write, research, or present orally in law;

- Assisting students to make use of examples and model answers;

- Explicitly advising students about referencing expectations;

- Teaching students how to work in groups or teams productively; and

- Modeling and providing structured opportunities for practising self and peer assessment.

Designing assessment so that it is clear about what is expected of students not only involves helping students to understand academic languages and conventions, it also involves helping students to understand standards in relation to tertiary level assessment. The timely provision of well written criterion referenced assessment (CRA) sheets is an important first step in articulating these expectations. However, the way in which the criteria and standards will be applied also needs to be explained in "dialogue" with students (ASKe, 2007). Ideally, students should be provided with opportunities to discuss and practise the application of the criteria in advance of assessment submission, to achieve a shared understanding of the performance criteria and standards.

Good practice in this regard can be demonstrated through the following two examples. First, expectations of tertiary academic writing can be demonstrated to students by "correcting" a piece of writing on the big screen in a lecture, using the track changes function for immediate feedback (Healy, 2008). Second, students can be provided with a marking scheme and asked to use the scheme to mark student assignments from a previous semester (Gleeson, 2008). An example of this intervention strategy in practice can be found on the UK-based Assessment Standards Knowledge exchange (ASKe) (2008). That strategy asks students to consider two sample assignments (one good, one average) on a related, but different, assignment topic, four weeks before the assignment is due. Students use an assignment guide 
and CRA sheet to individually mark the sample assignments, providing a mark and feedback. At a follow-up workshop a week later, the students discuss their individual marking approaches in small groups and agree as a group to a grade and feedback rationale. These results are fed back to the whole class, and students are given annotated and marked versions of the sample assignments. Rust, Price and O’Donovan (2003) found that Business School students at Oxford Brookes University who completed this non-compulsory intervention showed significant improvements in performance, which were sustained at a similar level one year later.

Designing assessment that engages students by scaffolding and integrating assessment within the curriculum

Student engagement can help reduce stress and anxiety around assessment in the first year. This can be achieved by designing assessment so as to scaffold and integrate it across and within the curriculum. Student engagement is enhanced because a scaffolded, integrated approach to assessment supports their learning in two critical ways. First, such intentional assessment design can support students' development of crucial assessment literacies and their discipline competence. Second, careful timetabling of assessment pieces across the first year program can support students to manage their academic workload effectively. Where assessment is designed at the first year level with these things in mind, it can be both challenging and achievable - high challenge delivered with high support (ACER, 2009) - in the sense that building complexity encourages "regular student engagement in learning activities in and out of class ... that become progressively more challenging" (Nicol, 2009, p. 6). Using assessment to engage students and support literacy development in this way can help address the high levels of psychological distress in law students.

Designing assessment as a scaffolded and integrated process within the curriculum requires assessment tasks to be cumulative and to increase in complexity over time. It also requires attention to providing the necessary resources and opportunities to support student skill development initially and for each cognitive increment. A practical example for achieving this can be found in the "patchwork texts" assessment device (Winter, 2003). This device requires students to produce several short pieces of work (such as a book review, a lecture summary with commentary, an account of a relevant experience) with a view to ultimately reflecting and integrating some or all of them in a "stitched together" final submission piece, having had the opportunity for peer feedback and editing along the way. Another possible approach is to break down a major assignment into smaller parts, with each individual part building a specific academic literacy (e.g. writing a bibliography or a research design proposal). Staggered due dates beginning early in the semester can make the tasks manageable in terms of workload, and enable prompt and constructive early feedback to enhance the development of individual academic literacies (Healy, 2008). For example, completion of a large essay assignment can be split into three stages: stage one might involve students discussing the essay question in groups in tutorials; stage two could require preparation of a draft essay plan and bibliography; with stage 3 involving the submission of the final essay (McCreery, 2005).

\section{Designing assessment to encourage students to be independent learners}

The transition for many school-leaver novice students from highly structured, directed learning environments to higher education settings where they are expected to be independent 
and autonomous learners is complex and highly stressful. Assessment can be harnessed as a particularly effective tool for assisting students to become independent, efficacious learners. Students who are independent and self-confident in their learning are more likely to be able to cope with the stresses of tertiary study. Below, we consider three ways in which assessment can be designed so as to encourage students to be independent learners: first, by offering students motivating, authentic assessment tasks; second, by encouraging selfreflection on the learning process; and third, by providing students with opportunities to take control of their own learning.

Authentic assessment tasks replicate the real world of work and practice. They are therefore more motivating and interesting for students in culturally, relational, and vocational ways; and they can help students with making or confirming program and career choices (Kift, 2008). There are many practical ways to design authentic assessment tasks. For example, given that many students' personal written communications (in their everyday lives) occur primarily in online contexts, it is culturally authentic to use online environments for written assessment (Bone, 2008). Further, authentic assessment can be provided through a focus on case studies which represent the common domains of the practice of a particular discipline (Nelson, 2008).

Integrating self-reflection into assessment design is another way of encouraging students to become independent learners. Self-reflection and self-assessment are critical to first year learners' self-efficacy and their ability to evaluate their own learning achievements and future learning needs; or, in other words, "to regulate their own learning" (Nicol, 2009, p. 37). There are many ways to integrate reflection into assessment design (McNamara, Field \& Brown, 2009). One simple practical approach is, for example, to require students to complete a self-reflection cover sheet for each written assignment, on which they rephrase the assignment question and self-assess their performance, including an estimate of the grade they expect (Nicol, 2009).

Finally, assessment design can encourage students to become independent learners by providing them with choice. This is because independence is fostered when learners are enabled to take control of their own learning. Choices regarding their learning can lead to "empowerment" (Nicol, 2009, p. 6), and empowerment is maximised when the choice extends to students being able to shape their assessment in ways that are meaningful to them. By providing students with opportunities to shape their assessment, student engagement can be enhanced and independent learning approaches encouraged. Even in first year, choice can be offered to students in terms of topic, timing, method, weighting, or assessment criteria.

This section has discussed how intentional assessment design can be used to reduce stress and anxiety around assessment in the first year curriculum. The strategies outlined above, if adopted and practised in legal education, have potential to provide a positive way forward in working to address the high levels of psychological distress that law students currently experience. Along with assessment design, approaches to providing timely and constructive feedback are also critical to supporting student learning in the first year. The next section explores how intentional feedback design can also help to address psychological distress in students. 


\section{Addressing the high levels of psychological distress experienced by law students through intentional feedback design strategies in the first year of legal education}

Feedback is central to supporting student learning. Yorke (2005), for example, refers to the importance of early formative feedback in terms of clarifying expectations and reassuring those students who doubt their ability to succeed. Therefore, in order to address student stress levels associated with academic performance and assessment at the tertiary level, it is critical to intentionally design feedback so that students are provided with regular formative commentary on their progress and achievement early in, and consistently across, their program of study.

If feedback is to be used effectively to support student learning, students need to understand what feedback is and how to make the best use of it. This sort of information can be provided to students in a range of ways, for example, in the form of a booklet that communicates the repertoire of feedback possibilities and their uses (Race, 2007). Intentional feedback design can also be supported by Taylor's (2008) assessment model for first year, that divides the semester into three overlapping assessment phases: assessment for transition (with low weight, low feedback), assessment for development (low weight, high feedback), and assessment for achievement (high weight, low feedback).

Importantly, capturing the potential of intentional feedback design in addressing psychological distress levels in students requires careful attention to two factors: the timing of feedback, and the process of feedback provision. Feedback is most useful when it is provided to students as soon as possible after submission-ideally within the first 24 hours (Race, 2009). This is because students can then still recall the detail of their submission and are more likely to understand how the feedback may be applied for future improvement. While large cohorts make this goal logistically difficult at the individual level, it is nevertheless possible to provide high quality generic feedback quite quickly and relatively efficiently to students. For example, online environments can be used to provide to an overview of a cohort's performance as trends start to emerge. It is also possible to develop generic feedback on key criteria, and to anticipate and address common mistakes (Race).

Receiving feedback early in the semester, especially before the census date in the Australian context, is particularly important to relieving student anxiety and establishing a sense of achievement. Setting minimally-weighted pieces of assessment early in the semester provides students with low-stakes opportunities to receive valuable formative feedback, which can then be applied to improve their performance on major assessment pieces later in the semester. For example, short weekly reflections as assessment that attract only a small percentage of the subject grade, can be used to provide students with important formative feedback (Westcott, 2008). A series of small assessment tasks can be set across a number of weeks of the semester that increase in complexity and weighting over time; beginning with a relatively simple task (which is not highly weighted) and building to the final, relatively complex task (which is more heavily weighted), with feedback provided each week (Healy, 2008). Another approach is to provide early, low-stakes assessment which is critically linked to and later informs higher-stakes assessment. For example, students might receive feedback on an essay plan that feeds into the final essay. Taylor's (2008) evaluation of an approach such as this indicates it effectively reduces student anxiety. 
Effective and intentional feedback design requires attention not only to ensuring that feedback is provided in a timely way, but also to ensuring that the way in which feedback is provided is optimised. Feedback to first year students can be optimised by preparing students for the types of feedback they can expect, delivering the feedback in appropriate and alternative ways, and by encouraging students to internalise the advice they receive and to act on it as a basis for future improvement in learning and assessment.

In terms of the types of feedback provided to students, ASKe research emphasises the need to reduce reliance on written feedback. Written feedback is "important when correcting errors, explaining technical points, and giving positive encouragement" but, without an accompanying dialogue (such as, in-class examination of exemplars or tutor-supported peer discussions), "rarely communicates tacit understandings about disciplinary content and academic literacy skills" (ASKe, 2007, p. 3). ASKe (2007; n.d.) offers the following additional suggestions to "make feedback work" by preparing students to engage with and use feedback:

- Align staff and student feedback expectations by explaining and reaching agreement about the purpose of feedback;

- Identify where, when, and what types of feedback students can expect;

- Provide specific examples of how feedback has been used previously by other students to improve their performance in subsequent assessment;

- Incorporate into assessment tasks the completion of a template in which students describe the feedback they received previously, and how they have applied it to the current task;

- Encourage peer discussion in small groups about feedback and how it will be used to improve subsequent assessment tasks;

- Provide feedback on draft (rather than final) assessment tasks, requiring students to demonstrate in the final assessment how the feedback was used to improve the work;

- Provide oral feedback via an audio mp3 file.

Other examples of optimal feedback provision include the following: engaging students by asking them to identify three specific areas on which they would like feedback, and then addressing those aspects (Nicol, 2009); posting examples of good student assessment tasks online for students to compare their own submissions against (Nicol); allowing students the opportunity to "re-write and re-submit" part of their assignment one week after receiving feedback, with additional marks available; providing feedback in a way that "encourages positive motivational beliefs and self-esteem" (FLAP, 2009, pp. 5-6) by ensuring that early feedback focuses on successes rather than mistakes; providing a range of feedback options and allowing students to select their preferred mode (Race, 2009); providing formative feedback without marks as grades often hamper student engagement with qualitative feedback; marks can then be made available after feedback has been read (Nicol).

\section{Conclusion}

Insufficient attention has been paid to date to supporting first year students to make the crucial transition to tertiary assessment practices and processes. In the context of legal education in particular, this contributes to, or exacerbates, the high levels of psychological distress that law students experience. This paper has argued that in order to address these high levels of psychological distress, it is necessary to harness intentional curriculum design, and in particular intentional design in relation to assessment and feedback. Many first year 
students of law under-perform in their assessments and find assessment very stressful, because they do not understand tertiary expectations or the specific requirements of writing and thinking like a lawyer. Too many students also are not receiving early formative feedback on their progress and are not being assisted to use the feedback they do receive to improve subsequent performance and learning. Intentional design of assessment and feedback practices provides a critical opportunity to support student learning in the first year, and thereby ameliorate the stressful nature of studying law.

\section{References}

Australian Council for Educational Research (ACER). (2009). Engaging students for success: Australasian student engagement report. Melbourne, Australia: Author. Retrieved August 13, 2009, from http://www.acer.edu.au/documents/AUSSE_ASERReportWebVersion.pdf

Australian Law Students Association. (2009). Depression in Australian law schools: A handbook for law students and law student societies. Retrieved February 2, 2010, from www.alsa.net.au/assets/publications

ASKe. (n.d.). Adopting a social constructivist approach to assessment in three easy steps! Oxford, UK: Oxford Brookes University. Retrieved July 14, 2009, from http://www.brookes.ac.uk/aske/documents/SocialConst.pdf

ASKe. (2007). How to make your feedback work in three easy steps! Oxford, UK: Oxford Brookes University. Retrieved July 14, 2009, from http://www.brookes.ac.uk/aske/documents/Make\%20FeedbackWork.pdf

ASKe. (2008). Improve your students' performance in 90 minutes! Oxford, UK: Oxford Brookes University. Retrieved July 14, 2009, from http://www.brookes.ac.uk/aske/documents/ASKe\%20Intervention.pdf

Beck, P. H. \& Burns, D. (1979). Anxiety and depression in law students: Cognitive intervention. Journal of Legal Education, 30, 270-290.

Benjamin, G. A. H., Kaszniak, A., Sales, B., \& Shanfield, S. B. (1986). The role of legal education in producing psychological distress among law students and lawyers. American Bar Foundation Research Journal, 11(2), 225-252.

Bone, A. (2008). Commentary on first year curriculum case studies: Assessment perspective. ALTC Exchange. Retrieved August 13, 2009, from http://www.altcexchange.edu.au/book/assessment

Brain and Mind Research Institute. (2009). Courting the blues: Attitudes towards depression in Australian law students and lawyers. Brain and Mind Institute Monograph 2009-1. Retrieved February 2, 2010, from http://www.cald.anu.edu/docs.

Britton, J. (2009, March). Lawyers, emotional distress and regulation. Panel on work-life issues at the Annual Conference of the Bar Association of Queensland, Gold Coast, Australia.

Brown, S. \& Knight, P. (1994). Assessing learners in higher education. London: Kogan Page.

First Level Assessment and Feedback Project. (2009). Designing first-year assessment and feedback: A guide for university staff. Leeds Metropolitan University. Retrieved August 13, 2009, from http://www.leedsmet.ac.uk/090601636503 Designing 1st Assessment_LoRes.pdf

Gleeson, D. (2008). Science (biology) case study. ALTC Exchange. Retrieved March 4, 2009, from http://www.altcexchange.edu.au/book/articulating-transition-pedagogy$\% \mathrm{E} 2 \% 80 \% 93$-science-biology-case-study-assprof-dawn-gleeson-university-m 
Hall, K. (2009). Do we really want to know? The importance of psychological wellbeing in Australian law schools. QUT Law and Justice Journal,9(1), 1-12.

Healy, A. (2008). Education case study. ALTC Exchange. Retrieved March 4, 2009, from http://www.altcexchange.edu.au/book/articulating-transition-pedagogy-educationcase-study-dr-annah-healy-queensland-university-tech

Hess, G. F. (2002). Heads and hearts: The teaching and learning environment in law school. Journal of Legal Education, 52, 75-111.

Iijima, A. L. (1998). Lessons learned: Legal education and law student dysfunction. Journal of Legal Education, 48, 524-538.

James, R., McInnis, C., \& Devlin, M. (2002). Assessing learning in Australian universities. Melbourne, Australia: Centre for the Study for Higher Education, University of Melbourne. $\quad$ Retrieved August 13, 2009, from http://www.cshe.unimelb.edu.au/assessinglearning/docs/AssessingLearning.pdf

Johnstone, R. \& Vignaendra, S. (2003). Learning outcomes and curriculum development in law: A report commissioned by the Australian Universities Teaching Committee. Retrieved February 2, 2010, from http://admin.carrickinstitute.edu.au/dspace/handle/10096/3492.

Kift, S. (2008, June). The next, great first year challenge: Sustaining, coordinating and embedding coherent institution-wide approaches to enact the FYE as "everybody's business." Keynote address presented at the $11^{\text {th }}$ Pacific Rim First Year in Higher Education Conference, "An Apple for the Learner: Celebrating the First Year Experience." Hobart, Australia. Retrieved March 4, 2009, from http://www.fyhe.qut.edu.au/past_papers/papers08/FYHE2008/content/pdfs/Keynote\% 20-\%20Kift.pdf

Kift, S. \& Nelson, K. (2005). Beyond curriculum reform: Embedding the transition experience. In Brew, A. \& Asmar, C. (Eds.), Proceedings of the 28th HERDSA Annual Conference. Higher Education in a Changing World: Research and Development in Higher Education (pp. 225-235). Milperra, NSW: HERDSA.

Krause, K-L., Hartley, R., James, R., \& McInnis, C. (2005). The first year experience in Australian universities: Findings from a decade of national studies. Melbourne, Australia: Centre for the Study for Higher Education, University of Melbourne. Retrieved February 24, 2009, from http://www.griffith.edu.au/_data/assets/pdf_file/0006/37491/FYEReport05.pdf

Lawrence, J. (2005). Re-conceptualising attrition and retention: Integrating theoretical, research and student perspectives, Studies in Learning, Evaluation, Innovation and Development, 2(3), 16-33. Retrieved August 13, 2009, from http://sleid.cqu.edu.au/viewissue.php?id=8

McCreery, C. (2005). Less is more: Rethinking assessment in a first-year history unit. Synergy, 22, 23-26. Retrieved August 13, 2009, from www.itl.usyd.edu.au/synergy/article.cfm?articleID $=265$

McNamara, J., Field, R. \& Brown, C. (2009, June). Learning to reflect in the first year of legal education: The key to surviving legal education and legal practice. Paper presented at the $12^{\text {th }}$ Pacific Rim First Year in Higher Education Conference, "Preparing for Tomorrow Today: The First Year Experience as Foundation." Townsville, Australia.

McNamara, J., Field, R., Cuffe, N. (2008, June). Designing reflective assessment for effective learning of legal research skills in first year. Paper presented at the $11^{\text {th }}$ Pacific Rim First Year in Higher Education Conference, "An Apple for the Learner: Celebrating the First Year Experience.” Hobart, Australia. 
Nelson, K. (2008). Information Technology case study. ALTC Exchange. Retrieved August 13, 2009, from http://www.altcexchange.edu.au/book/articulating-transitionpedagogy-\%E2\% 80\%93-information-technology-case-study-assprof-karen-nelsonqueen

Nicol, D. (2009). Transforming assessment and feedback; enhancing integration and empowerment in the first year. Mansfield, UK: The Quality Assurance Agency for Higher Education. Retrieved August 13, 2009, from http://www.enhancementthemes.ac.uk/documents/firstyear/First_Year_Transforming_ Assess.pdf

Orrell, J. (2005, November). Assessment literacy: A precursor to improving the quality of assessment. Paper presented at ATN Evaluations and Assessment Conference, Sydney, Australia. Retrieved June 23, 2009, from http://www.iml.uts.edu.au/EAC2005/speakers/Orrell.html

Race, P. (2007). Feedback. Leeds Metropolitan University. Retrieved August 13, 2009, from http://www.leedsmet.ac.uk/Feedback_Booklet_Phil_Race.pdf

Race, P. (2009, July). Putting feedback right: Getting better feedback to more students in less time. Paper presented at the Designs on Assessment Conference, Leeds Metropolitan University, UK. Retrieved June 23, 2009, from http://flap.teams.leedsmet.ac.uk/conference-23rd-june-2009

Rust, C., Price, M., \& O’Donovan, B. (2003) Improving students' learning by developing their understanding of assessment criteria and processes. Assessment and Evaluation in Higher Education, 28(2), 147-164.

Stuckey, R. T., Barry, M., Dinerstein, R. D., Dubin, J. C., Engler, R., Elson, J. S., Hammer, G., Hertz, R., Joy, P., Kaas, C., Merton, V., Munro, G., Ogilvy, S., Scarnecchia, S., \& Schwartz, M. H. (2007) Best practices for legal education: A vision and road map. Columbia, SC: Clinical Legal Education Association.

Sullivan, W., Colby, A., Wegner, J., Bond, L., \& Shulman, L. (2007). Educating lawyers: Preparation of the profession of law. San Francisco: Jossey-Bass.

Taylor, J. A. (2008). Assessment in first year university: A model to manage transition. Journal of University Teaching \& Learning Practice, 5(1), Article 3. Retrieved July 24, 2009, from http://ro.uow.edu.au/jutlp/vol5/iss1/3/

Thomson, J. (2007). Beating the blues. Law Society Journal, 45 (Sept), 18.

Watson, A. S. (1968). The quest for professional competence: Psychological aspects of legal education. University of Cincinatti Law Review, 37, 93-166.

Westcott, L. (2008). Law case study. ALTC Exchange. Retrieved March 4, 2009, from http://www.altcexchange.edu.au/book/articulating-transition-pedagogy-law-casestudy-ms-lisa-westcott-james-cook-university-australia

Winter, R. (2003). Contextualising the patchwork text: Addressing problems of coursework assessment in higher education. Innovations in Education and Teaching International, 40(2), 112-122.

Yorke, M. (2005). Increasing the chances of student success. In C. Rust (Ed.), Improving student learning: Diversity and inclusivity (pp. 35-52). Oxford, UK: Oxford Centre for Staff and Learning Development. 